Rhesus Monkey, Vol. II, p. 216 (Academic Press, New York, 1975)

39. Ways, P. O., Reed, C. F., and Hanahan, D. J.: Red cell and plasma lipids in acanthocytosis. J. Clin. Invest., 42: 1248 (1963).

40. Weinhold, P. A., and Villee, C. A.: Phospholipid metabolism in the liver and lung of rats during development. Biochem. Biophys. Acta, 106: 540 (1965).

41. The present address of Dr. T. E. Morgan is: Division of Biomedical Research, Association of American Medical Colleges, Suite 200, One Dupont Circle N.W., Washington, D.C. 20036 (USA).

Copyright (c) 1977 International Pediatric Research Foundation, Inc.
42. This research was supported by Grants HD-0057, HD-00747, RR00166, and Pulmonary SCOR HL-14152 from the National Institutes of Health.

43. Requests for reprints should be addressed to: W. Alan Hodson, M.D. Department of Pediatrics, University of Washington, Seattle, Wash. 98195 (USA).

44. Received for publication October $21,1976$.

45. Accepted for publication February 23, 1977.

Pediat. Res. 11: 1021-1026 (1977)

Bilirubin neonate

jaundice phototherapy

\title{
Effect of Intermittent Phototherapy on Bilirubin Dynamics in Gunn Rats
}

\author{
THOMAS P. VOGL, ${ }^{(20)}$ HOWARD CHESKIN, THOMAS A.BLUMENFELD, WILLIAM T. SPECK, \\ AND M. RICHARD KOENIGSBERGER
}

Department of Pediatrics, Columbia University College of Physicians and Surgeons, New York, New York, USA

\section{Summary}

To determine whether continuous phototherapy is necessary to control neonatal jaundice, groups of jaundiced (Gunn) rats were exposed to four blue light regimens: continuous light, 30 $\mathrm{min}$ light $/ 30 \mathrm{~min}$ dark, $6 \mathrm{~min}$ light $/ 6 \mathrm{~min}$ dark, and $6 \mathrm{~min}$ light $/ 18$ min dark. An exponential decrease in serum bilirubin concentration (SBC) was found with all regimens. A logarithmic dose response curve was obtained with a $50 \%$ light dose exhibiting $\mathbf{7 5 \%}$ efficacy, and a $25 \%$ light dose exhibiting $59 \%$ efficacy compared to continuous phototherapy. The time constants of the decrease in serum bilirubin concentration also varied logarithmically with doses with continuous therapy having a time constant of 1.4 days, and $6 \mathrm{~min}$ light/18 $\mathrm{min}$ dark therapy having a time constant of 3 days.

\section{Speculation}

In view of the concern which has been expressed over the potential long term side effects of phototherapy, the present study suggests that intermittent phototherapy, with a light cycle of approximately 30-60 min duration, and a concomitant dosage decrease of 50-75\% may effectively control neonatal hyperbilirubinemia.

The rate-limiting step of a major component of the mechanisms of phototherapy of hyperbilirubinemia may be the diffusion of bilirubin from blood to sites in the skin or the associated diffusion of bilirubin photoproducts out of the skin into the blood $(6,14)$. These diffusion processes occur slowly relative to the rapid $\left(<10^{-8} \mathrm{sec}\right)$ photochemical reaction of light with bilirubin $(3,8)$. We postulate that the light dosage inherent in continuous phototherapy may exceed that necessary to lower serum bilirubin concentration in neonatal jaundice and hypothesize that intermittent phototherapy may be equally as effective as continuous illumination. This study evaluates the effectiveness of three intermittent phototherapy schedules in reducing the serum bilirubin concentration of adult homozygous Gunn rats.

\section{MATERIALS AND METHODS}

Dorsally shaved adult homozygous Gunn rats were used for all experiments and phototherapy was administered using six Westinghouse Special Blue narrow spectrum fluorescent lamps (no. F20T12BB, Westinghouse Electric Company, Pittsburgh, Pa.). At the level of the rats these lamps produced a radiant flux (irradiance) of $0.014 \mathrm{~mW} / \mathrm{cm}^{2}$ at $310-390 \mathrm{~nm} ; 1.0 \mathrm{~mW} / \mathrm{cm}^{2}$ at $410-500 \mathrm{~nm} ; 0.15 \mathrm{~mW} / \mathrm{cm}^{2}$ at $500-565 \mathrm{~nm}$; and $0.045 \mathrm{~mW} / \mathrm{cm}^{2}$ at $635-700 \mathrm{~nm}$, as measured with a light meter constructed by one of us and calibrated against a fluorescent lamp at the $\mathrm{Na}$ tional Bureau of Standards $(1,16)$.

\section{CONTINUOUS PHOTOTHERAPY}

To determine the effect of continuous phototherapy an experimental group of six rats was studied during three 10-day periods: period 1, a control period of darkness; period 2, a period of continuous exposure to the phototherapy lights; and period 3 , a recovery period identical to the control period. A control group of two male and two female rats remained in subdued light ("dark") for 30 days. During the control periods referred to as "dark," the mean irradiances were $0.0008 \mathrm{~mW} / \mathrm{cm}^{2}$ at $310-390$ $\mathrm{nm} ; 0.01 \mathrm{~mW} / \mathrm{cm}^{2}$ at $415-465 \mathrm{~nm} ; 0.01 \mathrm{~mW} / \mathrm{cm}^{2}$ at $500-565$ $\mathrm{nm}$; and $0.005 \mathrm{~mW} / \mathrm{cm}^{2}$ at $635-700 \mathrm{~nm}$ derived primarily from low level, indirect white fluorescent room lights.

\section{INTERMITTENT PHOTOTHERAPY}

Six female experimental rats were studied during seven 10-day periods. These periods were: (1) a control period of darkness, (2) a 30-min light/30-min dark (30L/30D) phototherapy period, (3) a recovery period in the dark, (4) a 6-min light/6-min dark (6L/6D) phototherapy period, (5) a recovery period in the dark, (6) a 6-min light/18-min dark (6L/18D) phototherapy period, and (7) a recovery period in the dark. Simultaneously, four control rats received no phototherapy; however, on the last day of the second recovery period (period 5) one control rat died.

At the beginning of each experimental cycle, after $8 \mathrm{hr}$, and 


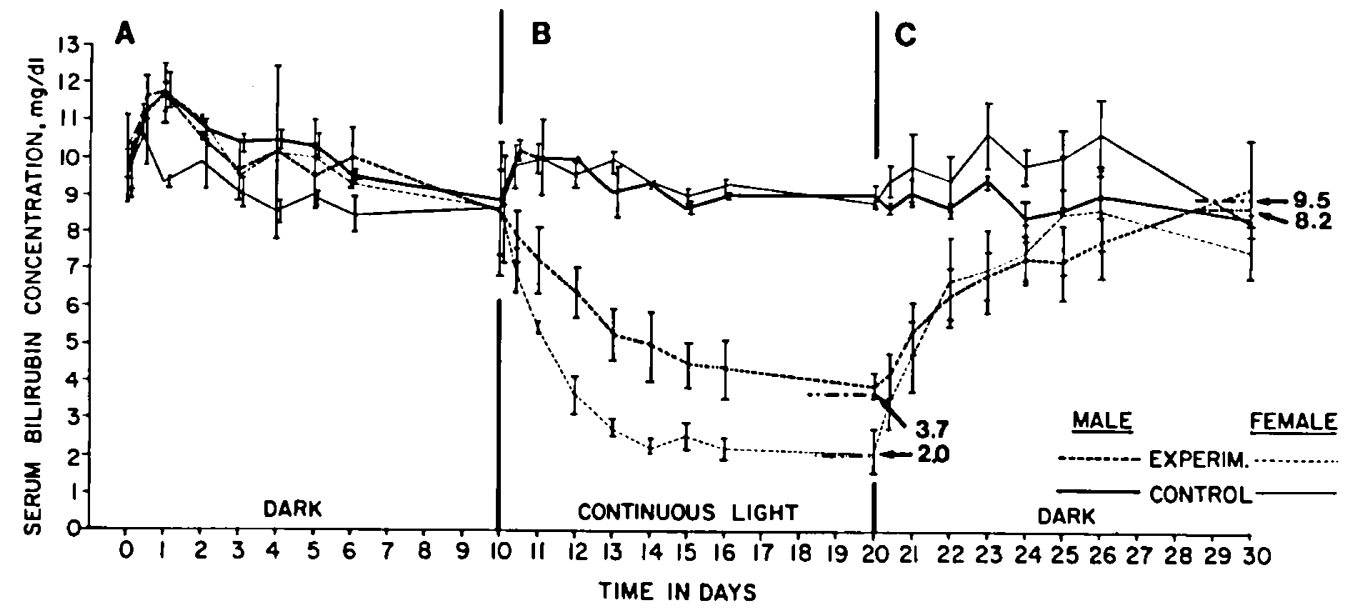

Fig. 1. Continuous phototherapy. Average serum bilirubin concentrations for three male and three female experimental rats and two male and two female control rats. Asymptotes were fitted to experimental rats' data as discussed in text. $A$ is period 1 (control, no phototherapy), $B$ is period 2 (continuous phototherapy), and $C$ is period 3 (recovery, no phototherapy). Error bars represent \pm 1 SD.

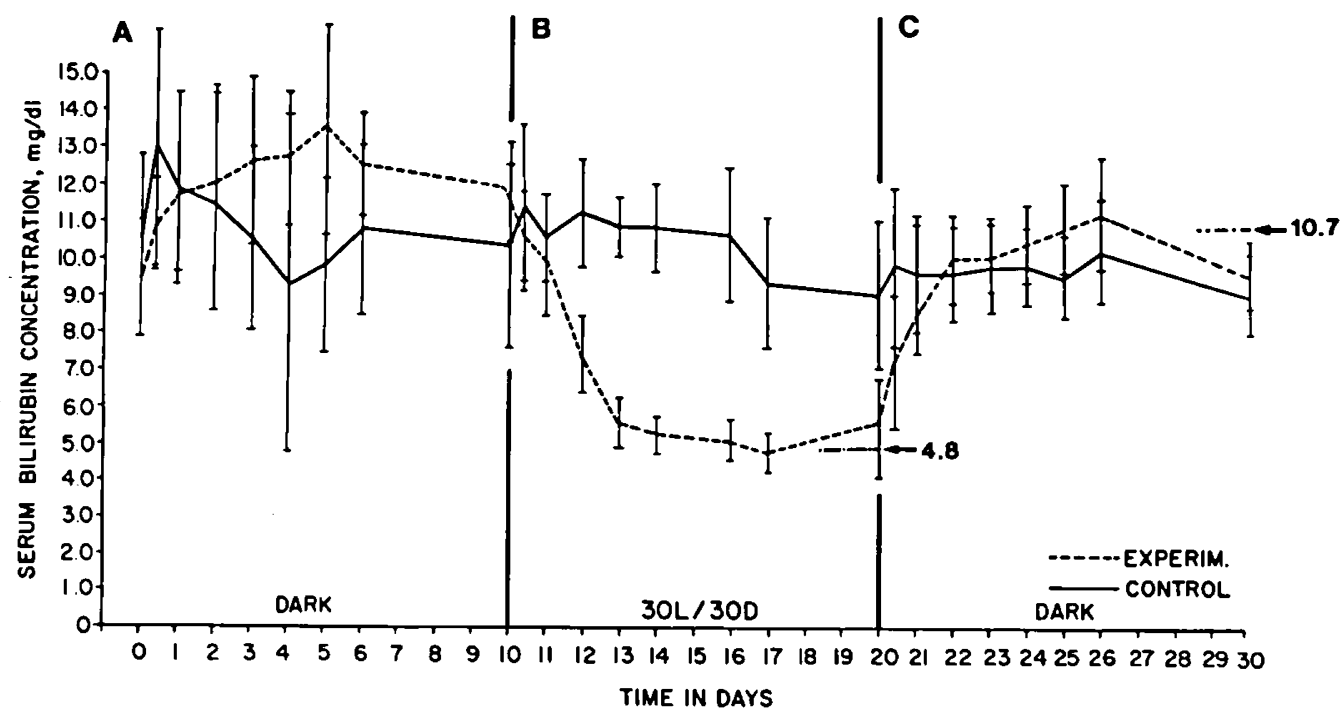

Fig. 2. Intermittent phototherapy. Average serum bilirubin concentrations for six female experimental rats and four female control rats. Asymptotes fitted as discussed in text. $A$ is period 1 (control), $B$ is period 2 ( $30 \mathrm{~min}$ light $/ 30 \mathrm{~min}$ dark), and $C$ is period 3 (recovery). Error bars represent $\pm 1 \mathrm{SD}$.

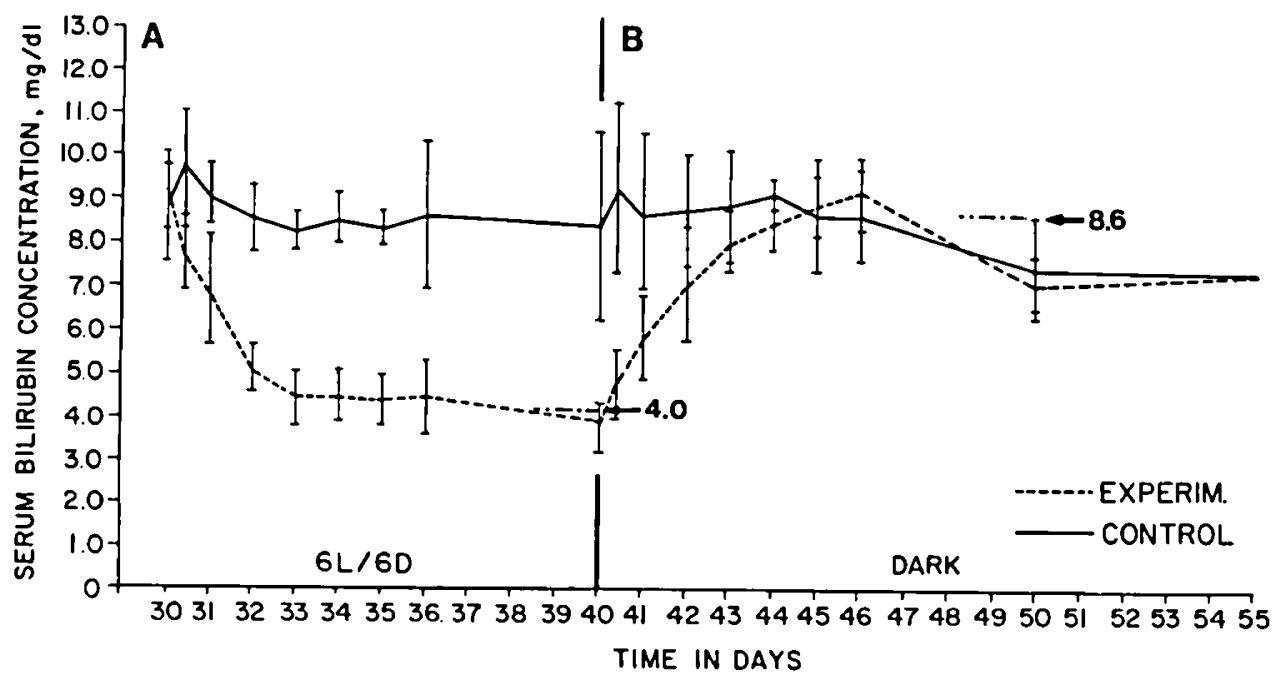

Fig. 3. Intermittent phototherapy. Average serum bilirubin concentrations for six female experimental rats and four female control rats. Asymptotes fitted as discussed in text. $A$ is period $4(6 \mathrm{~min}$ light $/ 6 \mathrm{~min}$ dark), and $B$ is period 5 (recovery). Error bars represent \pm 1 SD. 
after $1,2,3,4,5,6$, and 10 days, $200 \mu l$ blood were drawn from the tail vein of each animal. The samples were centrifuged, the hematocrit was determined, and the serum was stored frozen in darkness. A modified micro Jendrassik and Grof method using $50 \mu \mathrm{l}$ serum was used to determine total serum bilirubin concentration in all samples (4).

\section{RESULTS}

\section{CONTINUOUS PHOTOTHERAPY}

During the initial period of 10 days of darkness, SBC in the control groups remained stable at $10.6 \pm 0.9$ (mean $\pm \mathrm{SD}) \mathrm{mg} /$ $\mathrm{dl}$ for males and $9.3 \pm 0.8 \mathrm{mg} / \mathrm{dl}$ for females. In the experimental group, SBC also remained in constant range of $10.4 \pm 1.3$ $\mathrm{mg} / \mathrm{dl}$ for females and $10.3 \pm 0.9 \mathrm{mg} / \mathrm{dl}$ for males (see Fig. $1 A$ ).

During the succeeding 10 days of continuous phototherapy (period 2, Fig. 1B), the SBC showed an exponential decrease in the experimental group, to average steady state values (asymptotes) of $3.7 \mathrm{mg} / \mathrm{dl}$ for males and $2.0 \mathrm{mg} / \mathrm{dl}$ for females. During this period the SBC of control animals remained at $9.4 \pm 0.7$ (males) and $9.4 \pm 0.8 \mathrm{mg} / \mathrm{dl}$ (females). The fit to the simple exponential model and the determination of the asymptotes is presented in the section on data analysis.

During period 3 , a repeated 10 days of darkness (Fig. 1C), the SBC showed an exponential increase in the experimental group to average asymptotes of $9.5 \mathrm{mg} / \mathrm{dl}$ for males and $8.2 \mathrm{mg} / \mathrm{dl}$ for females. During this period the SBC in the control group remained at $8.8 \pm 0.6$ (males) and $9.6 \pm 1.0 \mathrm{mg} / \mathrm{dl}$ (females).

In this initial experiment with continuous phototherapy, the $\mathrm{SBC}$ of the female animals fell to lower levels than those of the

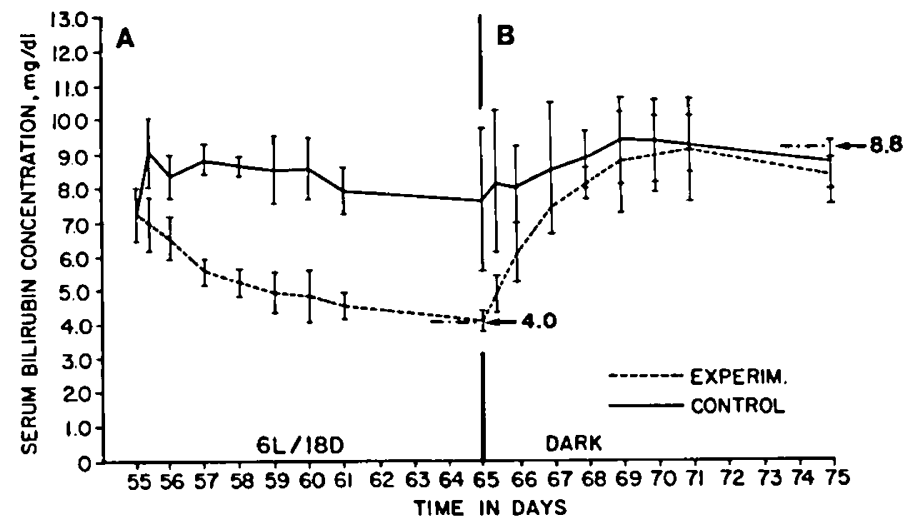

Fig. 4. Intermittent phototherapy. Average serum bilirubin concentrations for six female experimental rats and three female control rats. Asymptotes fitted as discussed in text. $A$ is period $6(6 \mathrm{~min}$ light $/ 18 \mathrm{~min}$ dark), and $B$ is period 7 (recovery). Error bars represent \pm 1 SD. males, an effect which has also been observed by other investigators (9). In order to minimize the experimental variability and obtain maximum sensitivity to phototherapy, only female rats were used in the subsequent intermittent phototherapy experiments.

\section{INTERMITTENT PHOTOTHERAPY}

During period 1,10 days of darkness, the SBC of the experimental animals remained constant at $11.9 \pm 2.3 \mathrm{mg} / \mathrm{dl}$ (Fig. $2 A$ ). During period $2,30 \mathrm{~L} / 30 \mathrm{D}$, the $\mathrm{SBC}$ of the experimental animals decreased exponentially with an average asymptote of $4.8 \mathrm{mg} / \mathrm{dl}$ (Fig. $2 B$ ). During period 3,10 days of darkness, the SBC of the experimental animals increased exponentially with an average asymptote of $10.7 \mathrm{mg} / \mathrm{dl}$ (Fig. $2 C$ ). In the control animals, remaining in darkness for 30 consecutive days, the SBC remained in a fairly constant range with slight decrease over these three periods (see Fig. 2).

During period $4,6 \mathrm{~L} / 6 \mathrm{D}$, the $\mathrm{SBC}$ of the experimental animals decreased exponentially with an average asymptote of $4.0 \mathrm{mg} / \mathrm{dl}$ (Fig. 3A). During period 5, 10 days of darkness, the SBC of the experimental animals increased exponentially with an average asymptote of $8.6 \mathrm{mg} / \mathrm{dl}$ (Fig. $3 B$ ). In the control animals remaining in darkness for 20 consecutive days, the SBC remained essentially constant over these two periods (see Fig. 3).

During period $6,6 \mathrm{~L} / 18 \mathrm{D}$, the $\mathrm{SBC}$ of the experimental animals decreased exponentially with an average asymptote of 4.0 $\mathrm{mg} / \mathrm{dl}$ (Fig. 4A). During period 7, 10 days of darkness, the SBC of the experimental animals increased exponentially with an average asymptote of $8.8 \mathrm{mg} / \mathrm{dl}$ (Fig. $4 B$ ). In the control animals remaining in darkness for 20 consecutive days, the SBC remained essentially constant over these two periods (see Fig. 4).

There appears to be an anomalous initial peak in the SBC's of the control animals. This point is taken $8 \mathrm{hr}$ after the start of phototherapy in the experimental animals, about 5 PM. All other points were taken between 8 and $10 \mathrm{AM}$. The possibility of the existence of a circadian rhythm of SBC suggests itself, but we have not investigated this hypothesis.

\section{DATA ANALYSIS}

An exponential equation of the form $S B C=a \exp (-b t)+c$ where $\mathrm{a}=$ decrease in $\mathrm{SBC}$ from beginning to asymptote during phototherapy $(\triangle S B C), b=$ time constant, in days ${ }^{-1}, t=$ elapsed time in days, and $c=$ asymptotic value of $S B C$, was fitted by a least squares method to the serum bilirubin measurements of each individual animal during each phototherapy period. Thus, values of $a, b$, and $c$ were determined for each animal by this method.

Since the SBC's of all the animals were not identical prior to initiation of phototherapy, a normalized SBC decrease was obtained by dividing the SBC decrease during phototherapy by the

Table 1. Coefficients of exponential equation fitted to phototherapy data ${ }^{1}$

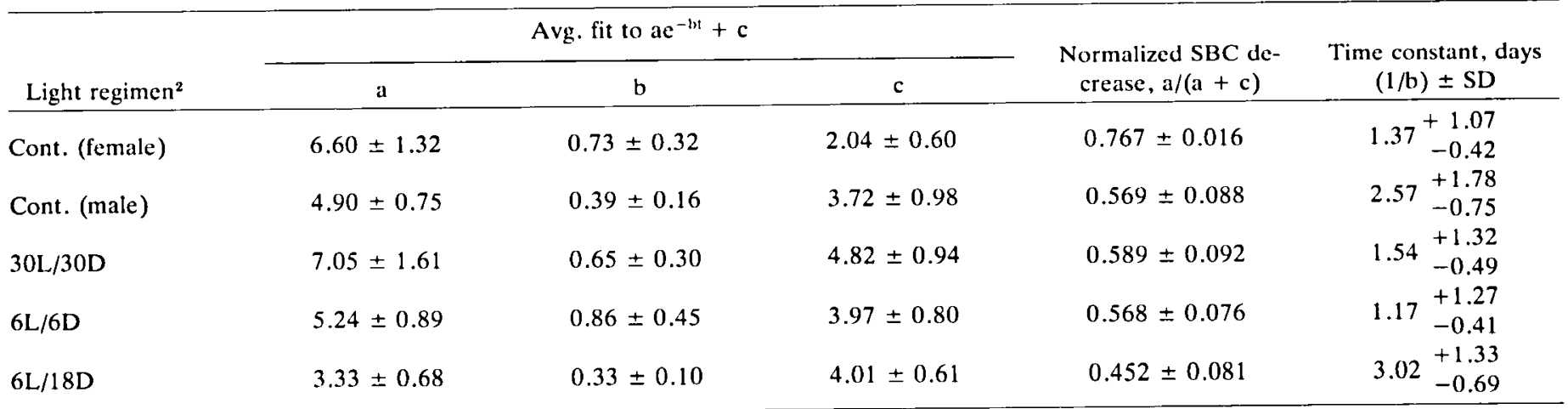

${ }^{1}$ SBC: serum bilirubin concentration; Cont.: continuous; L: light; D: dark.

${ }^{2}$ Duration of light and dark periods is measured in minutes. 


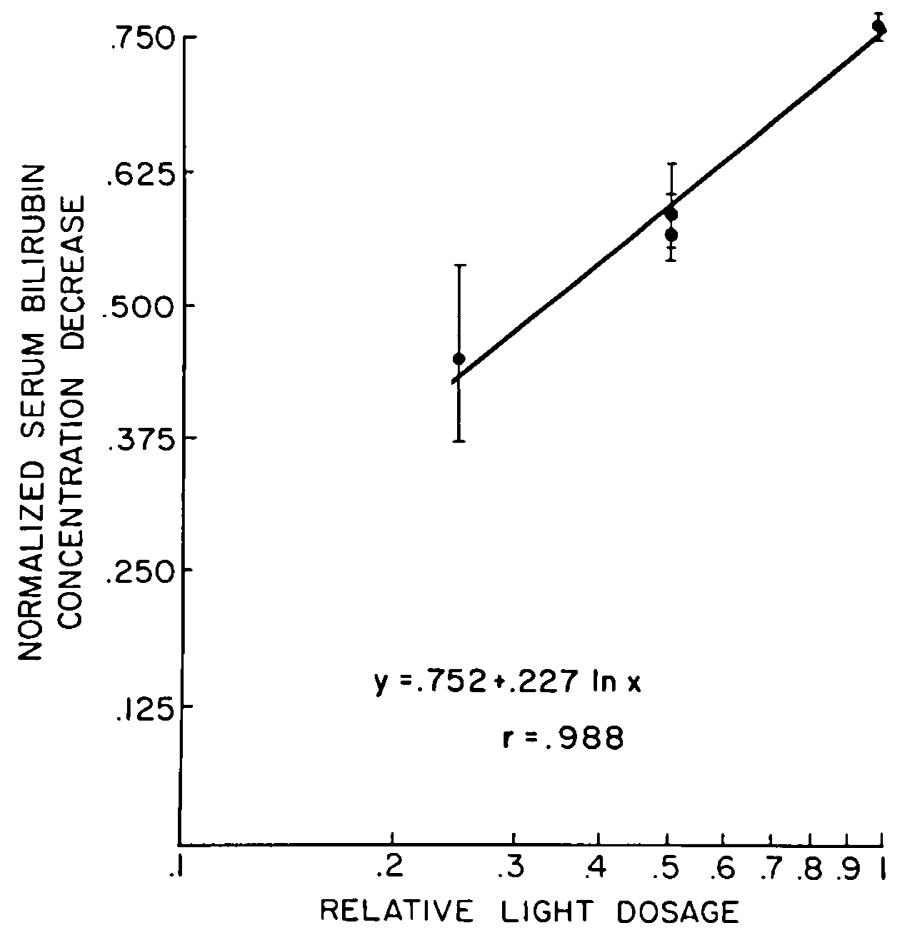

Fig. 5. Dose-response curve for phototherapy. Semilogarithmic plot of relative light dosage vs. average normalized serum bilirubin concentration decrease. Line and equation shown are least squares fit to 21 data points. Error bars represent $\pm 1 \mathrm{SE}$.

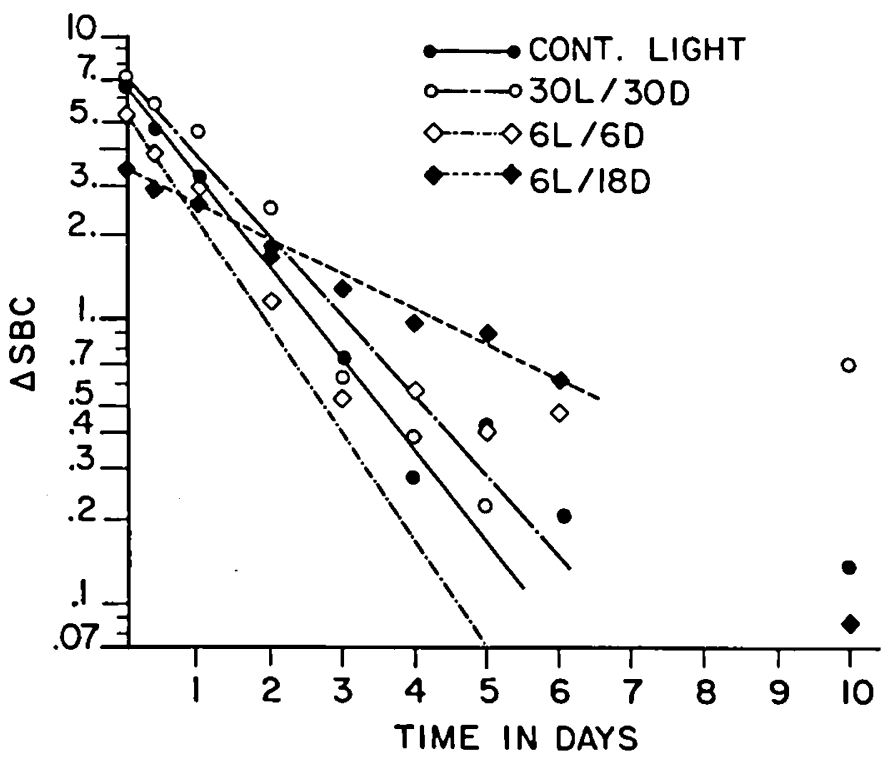

Fig. 6. Variation of serum bilirubin concentration $(S B C)$ with time. Semilogarithmic plots of SBC differences from asymptote during the four phototherapy periods. The lines are obtained from the exponential equations with coefficients from Table 1 for each phototherapy period. The apparent lack of fit of the $6 \mathrm{~min}$ light $/ 6 \mathrm{~min}$ dark data is the result of a point at day 10 which lies below the asymptote.

initial SBC $[a /(a+c)]$. The validity of this normalization was confirmed by lack of significant correlation between initial SBC values $(a+c)$ and the normalized SBC decrease $[a /(a+c)]$ for each phototherapy schedule and for the overall experiment.

The individual values of $a, b, c$, and $a /(a+c)$ obtained for each animal were then averaged after normalization in order to obtain average coefficients for the equation and a normalized SBC decrease for the whole population for each phototherapy

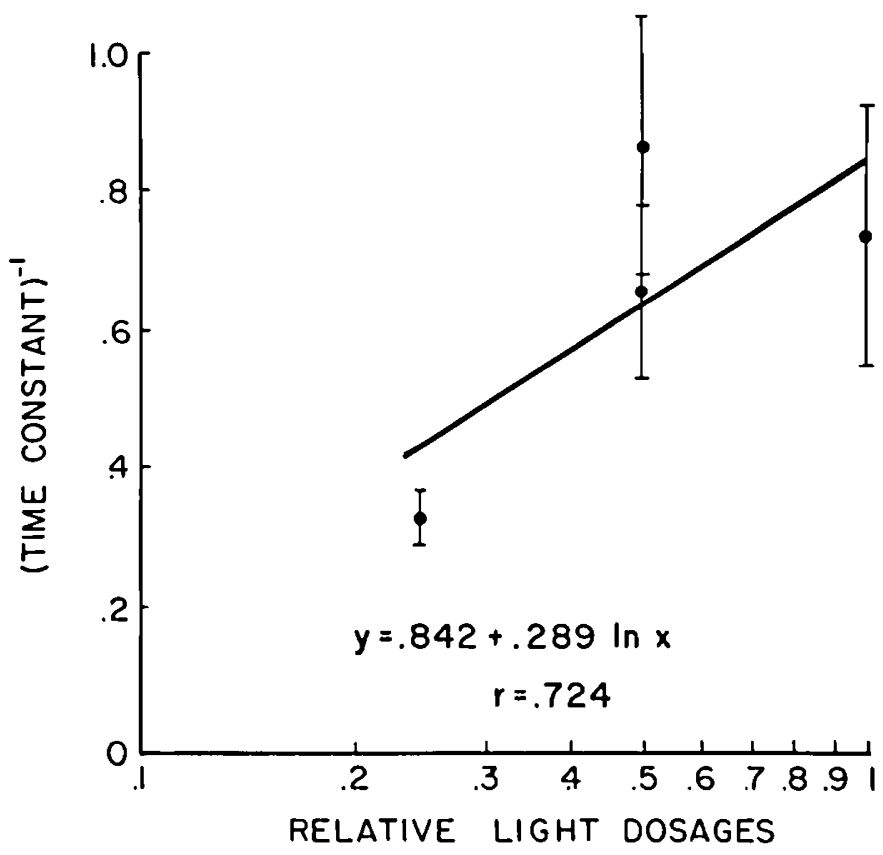

Fig. 7. Variation of the time constant with light dose. Semilogarithmic plot of relative light dosage vs. average reciprocal time constant $(1 / b)$ in days for serum bilirubin concentration decrease during phototherapy. Curve and equation of least squares fit to the 21 data points are shown. Error bars represent $\pm 1 \mathrm{SE}$.

schedule (Table 1). The averaged normalized SBC decrease was nearly identical for the $30 \mathrm{~L} / 30 \mathrm{D}$ and $6 \mathrm{~L} / 6 \mathrm{D}$ schedules, which are similar in that they both consist of a light dosage of 0.5 relative to continuous light. They result in a normalized SBC decrease of 0.59 and 0.57 , respectively. The $6 \mathrm{~L} / 18 \mathrm{D}$ schedule, a light dosage of 0.25 relative to continuous light, resulted in a normalized SBC decrease of 0.45 . Continuous phototherapy, a relative light dosage of 1 , resulted in a normalized SBC decrease of 0.77 . Thus a $50 \%$ decrease in light dosage resulted in a decrease in the effectiveness of phototherapy of only $25 \%$, and a $75 \%$ decrease in light dosage, an effectiveness decrease of only $41 \%$. An analysis of variance performed on the differences among these normalized SBC decreases revealed statistical significance $(P<0.001)$.

A semilogarithmic plot (Fig. 5) of relative light dosage of the above four schedules against normalized SBC decrease was obtained by least square fitting to the data from each rat in each of the phototherapy schedules (a total of 21 points). A logarithmic relationship yields the best fit with a correlation coefficient of 0.998 . A linear model gives a correlation of 0.804 and a power series model a correlation of 0.781 . An analysis of variance showed this logarithmic relationship to be significant $(P<$ 0.001 ).

\section{RATE OF CHANGE OF SERUM BILIRUBIN CONCENTRATION}

Semilogarithmic plots of the time variation of SBC of the female experimental rats during phototherapy are shown in Figure 6 . The agreement between the experimental points and the theoretical curves confirm the exponential nature of the SBC decrease for all phototherapy schedules. The appearance on day 4 of a change in slope for the continuous phototherapy group may have been due to a random variation, amplified by the logarithmic scale.

The slopes and time constants of the SBC decrement of all of the experimental animals under continuous and intermittent phototherapy are compared in Table 1. A semilogarithmic plot of relative light dosage against average slope values (b) for exponential decrease in SBC during phototherapy shows that a logarithmic relationship exists (Fig. 7). In spite of the small 
Table 2. Coefficients of exponential equation fitted to data from recovery periods ${ }^{1}$

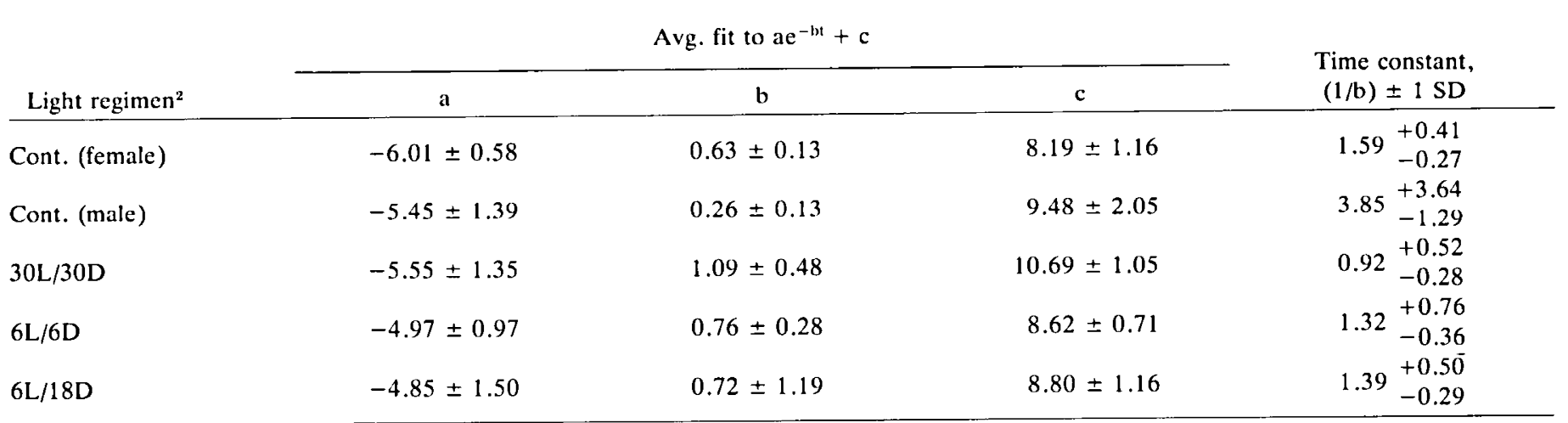

${ }^{1}$ Cont.: continuous; L: light; D: dark.

${ }^{2}$ Duration of light and dark periods is measured in minutes.

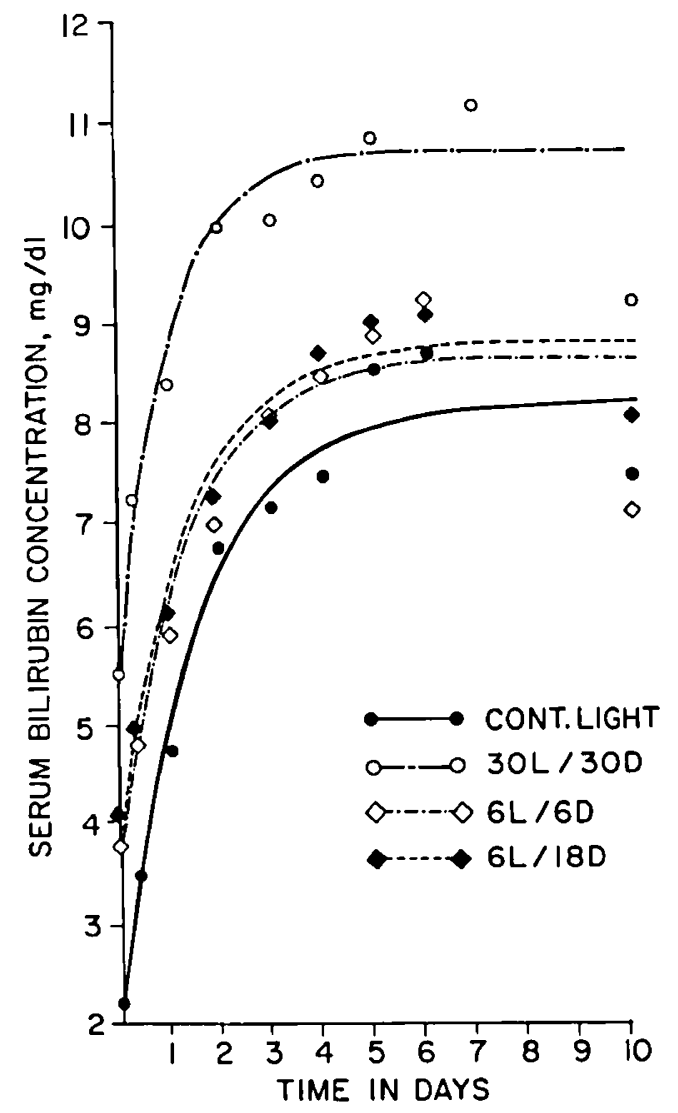

Fig. 8. Average serum bilirubin concentration changes of the experimental rats with time during recovery periods. Exponentials fitted to each recovery period are shown separately.

number of data points and the apparent variability of the effect of the 0.5 light dosage, an analysis of variance revealed this logarithmic relationship to be statistically significant $(P<0.05)$.

\section{RECOVERY PERIODS}

Exponential equations of the same form were fitted by a least squares method to the data from each animal's recovery periods in a manner similar to the SBC decrease under phototherapy. The coefficients of these equations were averaged for each recovery period (Table 2) and were plotted (Fig. 8).

Similar rates of increase in SBC for all recovery periods, independent of the preceding light schedules, can be seen. However, the consistent results from days 5 and 6 , which yield values lying above the computed asymptote, and values for day 10 , lying well below the asymptote, lead us to suspect that two time constants are involved in the recovery period but our data cannot, at present, resolve them adequately.

\section{DISCUSSION}

The time constants of SBC decrease during phototherapy reported here are in agreement with the time constants obtained by Ostrow (Fig. 2 of Ref. 10). Ostrow collected the bile directly by cannulating the common bile duct, thereby interrupting the enterohepatic circulation, whereas our animals had no surgical procedure. The fact that the time constants are similar in these two dissimilar experiments would imply that enterohepatic circulation contributes only secondarily to the observed time constants.

This series of experiments clearly indicates two effects of intermittent phototherapy on adult homozygous Gunn rats. (1) The dose response curve of SBC to the fraction of time that the light is on (that is to varying the dose at constant intensity) is logarithmic. The serum bilirubin concentration decrement reaches a plateau with increasing dosage. With decreasing dosage the effectiveness is not proportional to dose. Rather, $50 \%$ of the dose is $75 \%$ as effective and $25 \%$ of the dose is $59 \%$ as effective as continuous phototherapy under the experimental conditions used. (2) The time constant, i.e., the time required to reach a serum bilirubin concentration of 0.37 (1/e) of the initial concentration also varies logarithmically (and inversely) with the total dosage at constant intensity.

Clearly, more experiments, under a wider variety of intensities, wavelengths, and on/off periods, are needed before a comprehensive model of bilirubin dynamics under phototherapy can be firmly established and an optimum regimen suggested.

We can, however, conclude that for adult Gunn rats, and probably for neonates, an optimum combination of light intensity and on/off cycle time exists which represents a therapy regimen which produces optimal therapeutic benefit while minimizing total light dosage. In view of the several suggestions $(2,5$, $7,11,12,13,15)$ that phototherapy may have harmful long term side effects it is prudent to minimize the total light dosage to which the neonate is exposed consistent with effective therapy. These preliminary experiments with Gunn rats have paved the way for similar type experiments with a population of newborns in a hospital nursery. We are currently performing such experiments.

\section{CONCLUSION}

Intermittent phototherapy of homozygous Gunn rats with periodicity well below the apparent time constant of the effect exhibits a logarithmic dose-response curve if the dose is varied 
by changing the fraction of time that the light is on. The time constant of the decrease in serum bilirubin concentration also varies logarithmically with dose and doubles between continuous light and $25 \%$ light at constant irradiance.

\section{REFERENCES AND NOTES}

1. Behrman, R. E., Brown, A. K., Curry, M. R., Harber, L. C., Hastings, J. W., Odell, G. B., Schaffer, R., Setlow, R. B., Vogl, T. P., and Wurtman, R. J.: Final report of the Committee on Phototherapy in the Newborn. Available from NTIS, PB-237199 IAS (1974).

2. Clark, C. F., Torii, S., Hamamoto, Y., and Kaito, H.: The "bronze baby" syndrome: Postmortem data. J. Pediat., 88: 461 (1976).

3. Foote, C. S.: Photooxidation. In: Phototherapy of the Newborn: An Overview (National Academy of Sciences, Washington, D.C., 1974).

4. Jendrassik, L., and Grof, P.: Vereinfacte Photometrisch Methoden zur Bestimmung des Blutbilirubins. Biochem. Z., 297: 81 (1938).

5. John, E.: Complications of phototherapy in neonatal hyperbilirubinemia Aust. Paediat. J., 11: 53 (1975).

6. Kapoor, C. L.: Uptake and release of bilirubin by skin. Biochem. J., 136: 35 (1973).

7. Maurer, H. M., Fratkin, M., McWilliams, N., Kirkpatrick, B., Draper, D. Haggins, J. C., and Hunter, C. R.: Effect of phototherapy on platelet counts in low birthweight infants and on platelet production and lifespan in rabbits. Pediatrics, 57: 506 (1976).

8. McDonagh, A. F.: The photochemistry and photometabolism of bilirubin. In: Phototherapy of the Newborn: An Overview (National Academy of Sciences, Washington, D.C., 1974).

9. Odell, G. B., and Ostrow, J. D.: Personal communications.
10. Ostrow, J. D.: Photocatabolism of labeled bilirubin in the congenitally jaundiced (Gunn) rat. J. Clin. Invest., 50: 707 (1971).

11. Park, T. S., Padget, S., Fiorentino, T., Root, A. W., and Sisson, T. R. C.: Effect of phototherapy and nursery light on neonatal biorhythms. [Abstr.] Pediat. Res., 10: 429 (1976).

12. Speck, W. T., and Rosenkranz, H. S.: The bilirubin-induced photodegredation of deoxyribonucleic acid. Pediat. Res., 9: 703 (1975)

13. Speck, W. T., and Rosenkranz, H. S.: Intracellular DNA-modifying potential of phototherapy. [Abstr.] Pediat. Res., 10: 432 (1976).

14. Vogl, T. P.: On the dynamics of phototherapy. In: Proceedings of NIH Conference on Phototherapy for Hyperbilirubinemia - Long-Term Implications, April 24-25 1974. (To be published.)

15. Wu, P. Y. K.: Immediate and long-term effects of phototherapy on preterm infants. In: Phototherapy of the Newborn: An Overview (National Academy of Sciences, Washington, D.C., 1974).

16. The instrument consists of separate channels for each of the four spectral bands. Each channel consists of one or more Wratten filters defining the spectral band incident on a silicon photodiode. For the bilirubin band $(410-$ $500 \mathrm{~nm})$ a no. 34-A and no. 98 in series are used.

17. The authors gratefully acknowledge the partial support of this work by the National Foundation-March of Dimes (Research Grant 1-441) and by the Cerebral Palsy Foundation (Research Grant R-225-75).

18. Portions of this work were presented at the 4th Annual Meeting of the American Society for Photobiology, February 18, 1976, Denver, Colorado (Paper WPM-C1).

19. In partial fulfillment of the requirements for the M.S. degree in Bioengineering, Columbia University.

20. Requests for reprints should be addressed to: T. P. Vogl, Ph.D., Box 4, Babies Hospital, 630 West 168th St., New York. N. Y. 10032 (USA).

21. Received for publication November 3,1976.

22. Accepted for publication March 2, 1977.
Mononuclear cells newborn phosphoglycerate kinase phytohemagglutinin pyruvate kinase

\title{
Glycolytic Metabolism of Neonatal Mononuclear Cells
}

\author{
MAYA DAS, WAYNE KLEIN, AND STEPHEN A. FEIG ${ }^{(34)}$
}

Gwynne Hazen Cherry Memorial Laboratory and the Department of Pediatrics, UCLA School of Medicine, Los Angeles, California, USA

\section{Summary}

The mononuclear cells of newborn infants compared to those of normal adults contain diminished activity of pyruvate kinase (PK) $\left(14.9 \pm 1.2\right.$ vs. $22.3 \pm 1.3 \mu \mathrm{mol} / 10^{10}$ cells $\left./ \mathrm{min}\right)$ and phosphoglycerate kinase (PGK) (195 $\pm 10 \mathrm{vs.} 415 \pm 19)$. These deficiencies are accentuated in the cells of premature infants (4.9 $\pm 0,5$ and $71 \pm 15$, respectively) and are accompanied by reduced activity of adenylate kinase (AK) (14.8 \pm 1.9 vs. 33.6 $\pm 2.6)$. The activities of $A K$ and $P G K$ in adult and neonatal mononuclear cells are stimulated by phytohemagglutinin (PHA). Although the PK activity of adult cells is stimulated by PHA, the PK activity of neonatal cells is not. Mononuclear cell glycolysis is stimulated by PHA in both adults and neonates. The mean lactate production of neonatal cells is slightly lower than it is in adult cells $\left(93 \mathrm{vs} .110 \mu \mathrm{mol} / 10^{10}\right.$ cells/hr, unstimulated, and 151 vs. 181 , stimulated), but the differences are not statistically significant. The ATP content of neonatal cells $(3.8 \pm 0.4 \mu \mathrm{mol} /$ $10^{10}$ cells) is reduced compared to adult values $(6.0 \pm 0.3)$. Lactate production is directly correlated with $P K$ activity in adult and neonatal mononuclear cells. Neonatal mononuclear cell PK activity increases to adult levels during the first year of life.

\section{Speculation}

Glycolytic metabolism of neonatal mononuclear cells differs from that observed in adult cells. Pyruvate kinase may play a critical role in the energy metabolism of immunocytes. The observed increase in mononuclear cell PK activity to adult values in the middle of the first year of life may suggest a correlation of $P K$ activity with maturation of monocyte function.

Infection is a major cause of morbidity and mortality in newborn infants. The increased frequency and severity of infection in neonates suggests that a major predisposing factor may be an impairment of cellular immune function. Several observations lend support to this hypothesis. For instance, graft vs. host disease has been observed after intrauterine and exchange transfusions $(17,19)$. Furthermore, skin homograft rejection is delayed in the normal newborn (7) and Uhr et al. (25) have shown diminished rate and degree of skin sensitization to dinitrochlorobenzene in neonates. The passive transfer of skin reactivity to newborns is reduced (26), and Bonforte has described decreased reactivity to PHA in premature infants (3). 